COQUERY-VIDROVITCH, Catherine \& MESNARD, Éric. Être Esclave. Afriques-Amériques, $X V^{e}-X I X^{e}$ siècles

\title{
Samuel Lempereur
}

\section{OpenEdition}

Journals

Édition électronique

URL : https://journals.openedition.org/etudesafricaines/22012

DOI : 10.4000/etudesafricaines.22012

ISSN : $1777-5353$

\section{Éditeur}

Éditions de l'EHESS

\section{Édition imprimée}

Date de publication : 15 mars 2018

Pagination : 239-241

ISBN : 978-2-7132-2741-7

ISSN : 0008-0055

\section{Référence électronique}

Samuel Lempereur, « COQueRY-VIDRovitch, Catherine \& mESnARD, Éric. - Être Esclave. Afriques-Amériques, XVe-XIXe siècles », Cahiers d'études africaines [En ligne], 229 | 2018, mis en ligne le 15 mars 2018, consulté le 22 avril 2022. URL : http://journals.openedition.org/etudesafricaines/22012 ; DOI : https:// doi.org/10.4000/etudesafricaines.22012

Ce document a été généré automatiquement le 22 avril 2022.

(C) Cahiers d'Études africaines 


\title{
COQUERY-VIDROVITCH, Catherine \&
} MESNARD, Éric. - Être Esclave. Afriques-Amériques, $X V^{e}$-XIX ${ }^{e}$ siècles

\author{
Samuel Lempereur
}

\section{RÉFÉRENCE}

COQUERY-VIDROVITCH, Catherine \& MESNARD, Éric. - Être Esclave. Afriques-Amériques, XVe-

XIX ${ }^{e}$ siècles. Paris, La Découverte, 2013, 329 p., bibl.

1 Voilà un ouvrage qui fera date dans l'historiographie française de l'esclavage. L'étude historique de l'esclavage, et des traites négrières en particulier, a déjà une longue histoire, mais comme le soulignent les auteurs, ainsi qu'Ibrahima Thioub dans sa préface, celle-ci s'est trop souvent concentrée sur son aspect transatlantique et triangulaire, et donc celle des marchands européens. Le projet de Être Esclave est de remettre au centre de l'étude les acteurs majeurs de l'esclavage: les esclaves euxmêmes, ce qui fait tout le mérite et l'originalité de ce travail.

2 La principale thèse défendue dans cet ouvrage est de considérer les esclaves comme «acteurs essentiels». Il s'éloigne des tropismes classiques consistant à voir les Africains uniquement comme des victimes (tropisme misérabiliste) ou comme simples acteurs passifs du grand jeu de la Traite, ce qui, paradoxalement pour leurs défenseurs, renvoie les Africains à des hommes de seconde zone, incapables d'avoir un réel pouvoir d'agir sur la Traite. Il prend en compte les «trois partenaires de cette histoire de l'esclavage : les Européens, évidemment, mais aussi les Américains et les Africains » (p.18). On trouve développés sur trois chapitres les phénomènes de résistance à l'esclavage (sans pour autant tomber dans l'héroïsme béat) ; ceux de la créolisation en Afrique (les "Afro-Brésiliens») et en Amérique (les métis et «libres de couleur »). On trouve également les changements au sein de l'esclavage local africain ainsi que les chutes et émergences de divers royaumes en Afrique. Tout ceci tend à mettre en 
évidence les esclaves en tant qu'acteurs à part entière. Cette thèse n'est pas sans rappeler Olivier Pétré-Grenouilleau qui défendait en France un peu plus tôt « le fait que l'Afrique noire n'a pas été seulement une victime de la traite, elle a été l'un de ses principaux acteurs $»^{15}$. Ces résistances créatives d'esclaves, révoltes et cultures créoles, tendent à montrer que, malgré leur statut d'esclave, ils n'étaient pas pour autant des « choses » déshumanisées, comme on avait tenté de les rendre.

4 L'une des principales idées fausses battues en brèche par Être Esclave est celle du commerce triangulaire. Comme le suggère son sous-titre, Afrique-Amériques, ce livre insiste sur le commerce "en droiture ", celui qui ne passait pas par l'Europe et qui reliait directement l'Afrique au Brésil (principalement). Cet espace luso-africain, bien moins connu que l'espace atlantique, est pourtant responsable de $45 \%$ des esclaves vendus à travers l'Atlantique (soit environ 5 millions d'individus). Comme le souligne Ibrahima Thioub dans sa préface, le rappel de ce commerce est une véritable correction salutaire d'un biais historiographique qui était dommageable à la connaissance du système global des traites négrières.

5 Dans ce travail, en se focalisant autant sur l'Afrique que sur l'Amérique, les esclaves cessent d'apparaître sur les côtes comme par magie et sans passé historique. Le «Passage du milieu " n'est plus «un écran opaque entre deux espaces radicalement séparés » (p. 8) et l'histoire des royaumes africains liés à la Traite occupe toute sa place dans l'histoire pré-coloniale de l'Afrique et dans les transformations de ces sociétés dans le temps. Par là, ce travail est une pierre de plus apportée à un édifice réfutant, depuis déjà de nombreuses années, la vieille idée, aujourd'hui éculée dans les sciences sociales mais moins dans les discours politiques et quotidiens, d'une Afrique éternelle et traditionnelle dont les seuls changements auraient été, bon an mal an, ceux du fait de la colonisation.

Un autre apport essentiel de ce livre est de suivre le parcours de certains esclaves, dont les pérégrinations sont parfois très longues en Afrique avant d'être embarqués pour les Amériques. De tels documents ont déjà été utilisés dans la littérature anglophone (pensons notamment à Ralph Austen et Sandra E. Green) mais leur usage, en dehors des traductions de récits autobiographiques, est plus rare en français. Avec cette démarche, C. Coquery-Vidrovitch et E. Mesnard changent le regard porté sur la Traite, en le faisant passer des bateaux, ports négriers et marchands européens pour se centrer sur les esclaves eux-mêmes. Certains de ces récits concernent des captifs pris à l'intérieur des terres, vendus et revendus à plusieurs reprises, avant d'atterrir, parfois au bout de nombreuses années et au prix de multiples traversées de l'Afrique en toutes ses directions, dans un navire en partance pour l'autre côté de l'Atlantique. Tout en témoignant « du fait que les réseaux africains de traite traversaient le continent de part en part» (p. 280), ces récits montrent que les esclaves « ne devenaient pas esclaves sur les bateaux négriers" mais que "nombre d'entre eux l'étaient depuis parfois longtemps » (p. 91).

7 Enfin, ce travail s'insère dans un contexte social et politique fort de revendications mémorielles ou communautaires, des discours en compétition qui «saturent l'espace public et rendent difficilement audible la voix des sciences sociales» (p.9). En préférant un «travail de mémoire " plutôt qu'un « devoir », les auteurs de cet ouvrage proposent d'éviter par là erreurs et surenchères en apportant un savoir scientifique sur la table des discussions. 


\section{NOTES}

15. O. PÉTRÉ-GRENOUILLEAU, Les traites négrières : essai d'histoire globale, Paris, Gallimard, p. 556. 